\title{
Consideraciones críticas sobre el contrato administrativo en Brasil
}

\section{Critical considerations on the management contract in Brazil}

\section{ROGÉRIO GESTA LEAL*}

Resumen: Este trabajo trata sobre los límites teóricos, normativos y jurisprudenciales generales del Contrato Administrativo en Brasil, e intenta formular algunas críticas a su aplicación.

Palabras clave: contrato administrativo - fuentes normativas - fuentes jurisprudenciales.

Abstract: The object of this work concerns with the general theoretical, normative and jurisprudential limits of the Administrative Contract in Brazil, as well as it seeks to establish some critical aspects of its application.

Key words: Administrative Contract - Normative Matrices - Jurisprudential Matrices.

\section{CONTENIDO: NOTAS INTRODUCTORIAS.- I. LA NATURALEZA JURÍDICA DEL CONTRATO ADMINISTRATIVO EN CUANTO INSTITUCIÓN JURÍDICA.- II. LA DIFÍCIL COMPRENSIÓN DE LAS CLÁUSULAS INSTITUCIONALES DE LOS CONTRATOS ADMINISTRATIVOS EN BRASIL.- III. BIBLIOGRAFÍA}

\section{NOTAS INTRODUCTORIAS}

Pretendo en este ensayo abordar de manera panorámica algunos aspectos referidos a los contratos administrativos en Brasil, para verificar, en un primer momento, la regulación nacional y, en un segundo momento, las cuestiones jurisprudenciales que vienen orientando el debate jurídico nacional.

\footnotetext{
* Es juez de la Corte del Estado de Rio Grande do Sul, doctor en Derecho y profesor de la Universidad de Santa Cruz do Sul. También es profesor visitante en la Università Tulio Ascarelli - Roma Trè, en la Universidad de La Coruña (España) y en la Universidad Buenos Aires, además de profesor en la Escuela Nacional de Formación de la Magistratura (Escola Nacional de Formação e Aperfeiçoamento da Magistratura - enfam), miembro de la Red de Derechos Fundamentales (redir) del Consejo Nacional de Justicia de Brasilia, coordinador científico del Núcleo de Investigación Judicial de la Escuela Nacional de Formación de la Magistratura (Brasilia) y Consejero del Observatorio Brasileño de Justicia.
} 


\section{LANATURALEZAJURÍDICADELCONTRATOADMINISTRATIVO EN CUANTO INSTITUCIÓN JURÍDICA}

Hay un problema histórico y preliminar en la discusión sobre el contrato administrativo en cuanto institución jurídica, que consiste en la identificación o no de la singularidad de su objeto, de los sujetos que lo componen y de la naturaleza de la manifestación de voluntad de estos sujetos.

Antes de todo, conviene señalar que, en Brasil, la administración pública en cuanto contratante puede ser el gobierno federal, los estados, los municipios, el distrito federal, los territorios y todos los entes jurídicos que proveen servicios públicos. La parte contratista puede ser una persona física o jurídica que se dedique a cualquiera actividad de interés público y que goce de capacidad jurídica para contratar de acuerdo con las normas del Derecho civil.

El concepto de contrato administrativo en el Derecho administrativo brasileño es muy complejo. Comprende las relaciones o acuerdos que establezca la administración pública o quien haga sus veces con otro ente de la administración pública o con un particular. En estos casos, por fuerza de ley, de las cláusulas contractuales o del propio objeto de la relación jurídica, y con vistas a la protección del interés público, se privilegia al primero al otorgarle, bajo circunstancias muy especiales, la facultad de modificar unilateralmente la vigencia o las condiciones de ejecución del contrato, excepto en los casos en que el interés de la contraparte también sea público o se produzca un perjuicio económico desproporcionado ${ }^{1}$.

Bajo este marco conceptual, es interesante observar cómo Celso Antonio Bandeira de Mello ${ }^{2}$ distingue entre los contratos administrativos propiamente dichos y los contratos de Derecho privado de la administración; los primeros se rigen por el Derecho administrativo y los segundos por las normas del Derecho privado. Como ejemplo de un contrato administrativo propiamente dicho, cita la concesión de un servicio público y, como ejemplo de un contrato de Derecho privado de la administración, menciona la compra-venta 3 .

Ya Maria Sylvia Zanella Di Pietro ha sustentado la existencia de contratos administrativos en el sentido amplio empleado por la ley 8.666/93

1 En este sentido, véanse los trabajos de Lima, Ruy Cirne. Princípios de Direito administrativo. Porto Alegre: Globo, 1984; Martins, Lúcio. Reforma da administração pública e cultura política no Brasil: uma visão geral. Brasilia: Enap, 1997; Medauar, Odete. Direito administrativo moderno. São Paulo: Revista dos Tribunais, 1998.

2 Bandeira de Mello, Celso Antônio. Curso de Direito administrativo. São Paulo: Malheiros Editores, 2006, p. 439.

3 Lúcia Valle Figueiredo sostiene la posibilitad del ordenamiento nacional de contar con modalidades distintas de contratos administrativos, pues existen los llamados "contratos da administración pública" que están bajo una mayor influencia de las normas Derecho privado, aunque aún sufran fuerte interferencia del derecho público; y los llamados "contratos administrativos", que están enteramente sujetos al Derecho público. En Figueiredo Valle, Lúcia. Curso de Direito administrativo. São Paulo: Malheiros, 1999, p. 467. 
y de contratos administrativos en sentido estricto, los cuales abarcan solamente aquellos acuerdos en los que la administración es parte bajo el régimen público, derogatorio y exorbitante, fuera del Derecho común. Sin embargo, seguidamente arriba a la conclusión de que el contrato administrativo en sentido amplio ha quedado casi totalmente derogado, dado que el legislador ha determinado que en la mayoría de los contratos en los que la administración es contratante mantiene su supremacía sobre la contraparte privada 4 .

De cualquier modo, hasta los administrativistas más liberales como Carlos Sundfeld han sostenido que "en cualquier caso, la regla es clara: los contratos de la Administración, listados o no en los artículos 1ำ e 62, párrafo 3o, están bajo al régimen típico del contrato administrativo en sentido estricto". ${ }^{5}$

Con base a este razonamiento, este renombrado administrativista ha insistido en que los privilegios concedidos a la administración están vinculados con la práctica de actos unilaterales, inherentes a las competencias públicas que inciden sobre el objeto del contrato. Es solo por este motivo que en las cláusulas contractuales o en las normas referentes a los contratos celebrados por la administración pública se prescinde de menciones específicas a los privilegios, pues estos de desprenden de la naturaleza pública e indisponible del objeto, que ya fue objeto de ley federal ${ }^{6}$.

La preponderancia del interés público y la consecuente mutabilidad de los contratos administrativos (poderes de inestabilidad) se derivan directamente de las reglas de competencia administrativa relativas a los servicios públicos y al uso de bienes públicos, y son inderogables por la voluntad de las partes y no susceptibles de transacción.

A pesar de que esta interpretación doctrinal de los contratos administrativos es minoritaria en nuestro escenario nacional, no puede negarse que estos difieren de las relaciones contractuales privadas, sea porque una o ambas partes son entes de la administración pública o porque el objeto del contrato siempre involucra el interés público, con lo cual queda fuera del ámbito del Derecho civil y sometido al régimen jurídico del Derecho público.

De esta forma, lo que caracteriza al contrato administrativo no es solo la finalidad, el objeto o el interés público. Es, sobre todo, la participación de la administración actuando publicae utilitatis lo que deroga las normas de Derecho privado y, bajo la égida del Derecho público, tipifica al contrato 
administrativo. En este orden de ideas, Hely Lopes Meirelles ${ }^{7}$ define el contrato administrativo en sentido amplio como la concertación entre la administración pública — actuando bajo esta cualidad-y un particular u otro ente administrativo, para la consecución de objetivos de interés público, en las condiciones deseadas por la propia administración.

En el Derecho brasilero, de manera general, la teoría del contrato administrativo ha seguido las pautas del Derecho francés, y se ha consolidado la concepción de que los contratos celebrados por la administración pública tendrían naturaleza administrativa siempre que atendiesen al menos a uno de estos tres requisitos: (a) estar calificado por ley como tal, (b) tener por objeto la ejecución de un servicio público y (c) contener las mencionadas cláusulas exorbitantes 8 .

A parte de las críticas que se presentarán acerca de estos elementos, es posible concluir que en los contratos en que el poder público es parte: (a) es imperiosa la proyección de las normas constitucionales y infraconstitucionales que rigen la administración pública, ya que son indisponibles y vinculantes y, por lo tanto, deben ser consideradas aunque no haya cláusula contractual expresa en este sentido; (b) la facultad para modificar (poderes de inestabilidad) se presenta de manera independiente a cualquier previsión contractual o normativa expresa.

¿Y por qué sucede esto? Esto deriva del hecho que la naturaleza del objeto de la administración pública (el interés público), no se identifica con la voluntad/propiedad del administrador o del Estado sino, más bien, pertenece al titular último de la soberanía material: la sociedad. De esta manera, dado que la administración no detenta la titularidad del bien público que se define aquí como el interés público-, les es posible hacerse cargo solamente de la gestión del patrimonio por delegación de competencias?. Esta gestión, a su vez, también está condicionada por los objetivos y finalidades predefinidas, constitucional e infraconstitucionalmente ${ }^{10}$.

En el plano constitucional, hay que señalar las disposiciones del título primero de la Constitución Federal (artículos 1 a 4), denominadas "Principios fundamentales", que definen la República Federativa Nacional como un Estado democrático de Derecho y establecen sus fundamentos, objetivos e principios ${ }^{11}$. Estos principios, por un lado, sirven como

7 Meirelles, Hely Lopes. Licitações e contratos administrativos. São Paulo: Malheiros, 2004, p. 156.

8 Cretella Jr., José. "Os cânones do Direito administrativo". Revista de Informação Legislativa, № 97, Janeiro/Março de 1988, pp. 05/52, Brasilia.

9 En este sentido, véase Figueiredo, Lucia Valle. Curso de Direito... Ob. cit., p. 63. De igual modo, Alessi, Renato. Instituciones de Derecho administrativo. Buenos Aires: Casa Editorial, 1990; Bielsa, Rafael. Derecho administrativo. Buenos Aires: La Ley, 1975; Bonnard, Roger. Précis de Droit administratif. París: Libraire du Recueil Sirey, 2001; Cavalcanti, Themístocles Brandão. Tratado de Direito administrativo. São Paulo: Freitas Bastos, 1986.

10 He tratado este tema en mi libro Estado, administração pública e sociedade: novos paradigmas. Livraria do Advogado, 2008.

11 Conforme discutí en mi libro Teoria do Estado: cidadania e poder político na modernidade. Porto Alegre: Livraria do Advogado, 2001. 
muro de contención contra actos antidemocráticos y violaciones a los derechos fundamentales, y deben ser respetados por todos en cualquier condición; por otro lado, constituyen objetivos a ser logrados por las autoridades a quienes se asignan tales responsabilidades, en particular, las autoridades estatales. En efecto, las disposiciones constitucionales programáticas, aun cuando carecen de eficacia real, no pueden dejarse fuera de la sensibilidad del mercado y las relaciones de producción. Por el contrario, deben contar con la mediación estatal-gubernamental del Estado democrático de Derecho, en sentido proveedor/interventor y, por supuesto, con la capacidad de movilización y diálogo de la sociedad civil organizada.

Los principios fundamentales, junto con las disposiciones del artículo 37 de la Constitución de 1988 y otros preceptos dispersos en este texto, en cuanto normas vinculantes, predeterminan todas las acciones del Estado (creación y desarrollo de políticas públicas, actos administrativos, legislativos y judiciales) de acuerdo con las pautas, límites y direcciones derivados de tales principios. De esta forma, es posible afirmar, en términos metodológicos, que el acercamiento y la elaboración de los actos administrativos deben venir — siempre y continuamente- precedidos de los exámenes de constitucionalidad y legalidad que se realizarán por medio de su confrontación con los fundamentos y objetivos del Estado democrático de Derecho brasileño, descritos en tales principios y reglas jurídicas.

Por lo tanto, cuando la administración pública actúa — sea celebrando contratos administrativos o cumpliendo con sus deberes normativos y políticos ${ }^{12}$ - puede hacerlo respetando y persiguiendo las directrices constitucionales contenidas en los principios fundamentales, bajo riesgo de incurrir en conductas inconstitucionales e ilegales por acción u omisión.

Los actos administrativos — como género- deben ajustarse a los mencionados principios, pues estos constituyen la condición de su existencia; son la causa o fuente del propio sistema jurídico y del Estado. Así, una posible violación de estos principios por los actos administrativos implica su ilicitud e ilegitimidad, lo que puede ser objeto de investigación por la vía administrativa o por la jurisdiccional ${ }^{13}$.

12 Que se define aquí como pertenecientes a la supremacía del interés público de la mayor parte de la población y su indisponibilidad.

13 El Consejo de Estado francés, al tratar de cuestiones administrativas desde esta perspectiva, ya ha señalado que un acto administrativo o reglamento que viola un principio jurídico configura el mismo tipo de invalidez que la violación de una norma positiva. En este sentido, véase la obra de Rivero, Jean. Droit administratif. París: Dalloz, 1981, p. 135. En Brasil, por ejemplo, el Tribunal Superior de Justicia ha afirmado que los principios y derechos fundamentales a la vida y la salud son derechos subjetivos inalienables, reconocidos constitucionalmente, cuya primacía, en un Estado democrático de Derecho como el nuestro, que reserva especial protección a la dignidad humana, debe superar cualquier tipo de restricciones legales. Recurso especial 836913/RS, recurso especial 2006/0067408-0, 1 ${ }^{\text {a }}$ Turma, relator Min. Luiz Fux, juzgado el 08 de mayo de 2007 y publicado en el Diário de Justiça del 31 de mayo de 2007.

CONSIDERACIONES CRÍTICAS SOBRE

EL CONTRATO

ADMINISTRATIVO

EN BRASIL

CRITICAL

CONSIDERATIONS

ONTHE

MANAGEMENT

CONTRACT IN

BRAZIL 
En vista de estas consideraciones es que se ha afirmado que, una vez formado por la voluntad humana libre, el interés particular es disponible, y se halla sujeto únicamente a las restricciones impuestas por la norma jurídica — véase que la disponibilidad impera en el campo del Derecho privado, pues está sometida a la voluntad del dominus—; se diferencia del interés público precisamente porque este es conformado por la finalidad pública previamente fijada por el ordenamiento jurídico vinculante que la rige. Si en el Derecho privado prevalece la voluntad, en el Derecho administrativo la finalidad es el elemento informador de las posibilidades de acción u omisión estatal ${ }^{14}$.

En el plano infraconstitucional, es la ley federal 8.666/93 (artículo 54) y sus modificatorias delimitan los contornos normativos del contrato administrativo nacional.

Entre los muchos temas polémicos que trae la regulación de los contratos administrativos, una de las cuestiones más candentes refiere a lo que denomino las "cláusulas institucionales", que seguidamente pasaré a examinar, para luego delimitar de la mejor manera las posibilidades de subsunción de las causas de invalidez, ineficacia e inexistencia de los negocios jurídicos practicados por la administración pública, así como las situaciones en que la resolución de estos se impone.

\section{LA DIFÍCIL COMPRENSIÓN DE LAS CLÁUSULAS INSTITUCIONALES DE LOS CONTRATOS ADMINISTRATIVOS EN BRASIL}

En Brasil, hace mucho tiempo, la interpretación doctrinal más tradicional sobre los contratos administrativos ha sostenido que, por involucrar intereses públicos indisponibles y contar con el poder público como contratante, sus cláusulas reclaman un carácter peculiar, que en nada desbordan el sistema jurídico nacional, sino, por el contrario, se encuentran regulado por este. Considerando que la administración pública, por lo general, solo posee poderes institucionales como herramienta para realizar la finalidad a la cual está inseparablemente vinculada — de ahí la afirmación de que desempeña un munus público-, tiene, en realidad, deberes-poderes y encuentra la tónica, conforme lo señalan Bandeira de Mello ${ }^{15}$ y Alessi ${ }^{16}$, en los deberes.

Por estas razones, se imponen cautelas especiales cuando se encuentran en juego recursos e intereses públicos, sin descuidar, por supuesto, los derechos subjetivos de terceros igualmente protegidos por el

14 Veáse el texto de Di Cammerata, Roehrssen. I Contratti della publica amministrazione. Boloña: Nanichelli Editore, 1989.

15 Bandeira de Mello, Celso. Curso de Direito...Ob. cit., p. 57.

16 Alessi, Renato. Principi di Diritto amministrativo. Milán: Giuffrè, 1990, p. 82. 
ordenamiento jurídico nacional. La ecuación que se construirá en virtud de estos factores, por una parte, será mediada por los principios y las normas constitucionales e infraconstitucionales vigentes; y, por otra parte, estará sujeta a juicios razonables aplicables a cada caso concreto.

Pretendo, pues, denominar a las posibles cláusulas contractuales de protección de los intereses públicos como cláusulas institucionales ${ }^{17}$ ya que efectivamente representan contenidos ubicados por encima de la libertad de las partes involucradas en el contrato, e imponen formalidades y contenidos. Además, como ya he dicho, si estas cláusulas exceden el Derecho común para reconocer una condición especial a la administración pública, por lo general, constituyen restricciones a las ventajas o poderes que podría tener el contratista, que derivan de normas jurídicas válidas e eficaces que demandan, además, de una interpretación y aplicación sistemática e integrada a todo el sistema jurídico.

Las principales cláusulas institucionales, en cuanto normas jurídicas, son las que establecen las posibilidades de:

- modificar unilateralmente las condiciones del contrato para asegurar una mejor adecuación a las finalidades del interés público, al respetar los derechos del contratista;

- rescindirlo unilateralmente en los casos fijados en el inciso I) del artículo 79 de la ley;

- inspeccionar y controlar su ejecución;

- aplicar sanciones para los casos de cumplimiento parcial o incumplimiento;

- en los casos de los servicios esenciales, ocupar temporalmente bienes muebles, inmuebles, personal y servicios vinculados al objeto contractual, en los supuestos en los que haya necesidad de garantizar la verificación de faltas por parte del contratista, así como en caso de rescisión ${ }^{18}$.

17 Me voy a referir a lo que la doctrina brasileña del Derecho administrativo — arriba citada — llama de "cláusulas exorbitantes". Yo prefiero tratarlas como preceptos de regulación institucional, pues fueron normativamente establecidos por ley federal, a toda la administración pública en Brasil, como petición de principio en la gestión de un interés que reclama trato y protección especiales en vista de sus peculiaridades.

18 Se refiere al artículo 58 de la ley 8666/93, que dispone: "El régimen jurídico de los contratos administrativos establecido por esta Ley a la Administración, con relación a ellos, la prerrogativa de: I - modificarlos, unilateralmente, para adaptarse mejor a los fines del interés público, respetando los derechos del contratista; II - rescindirlos de manera unilateral en los casos especificados en el numeral I del artículo 79 de esta Ley; III - supervisar su ejecución; IV - aplicar sanciones motivadas por el incumplimiento total o parcial del contrato; $\mathrm{V}$ - en los casos de servicios esenciales, ocupar temporalmente los bienes muebles, inmuebles, personal y servicios vinculados al objeto del contrato, en la hipótesis de que haya la necesidad de garantizar la apuración de faltas por parte del contratista, así como en la hipótesis de rescisión del contrato administrativo. § 1o Las cláusulas económico-financieras y monetarias de los contratos administrativos no podrán ser alteradas sin previo consentimiento del contratista. § 20 En la hipótesis del numeral I de este artículo, las cláusulas económico-financieras del contrato deberán ser revisadas para mantener el equilibrio contractual".

CONSIDERACIONES CRÍTICAS SOBRE

EL CONTRATO

ADMINISTRATIVO

EN BRASIL

CRITICAL

CONSIDERATIONS

ONTHE

MANAGEMENT

CONTRACT IN

BRAZIL 
El poder de modificar unilateralmente el contrato tiene su contenido y alcances fijados en la ley. Por lo tanto, es aplicable, por ejemplo, cuando se produzca una alteración del proyecto inicial o de las especificaciones para adaptarse técnicamente a sus objetivos; o cuando haya necesidad de cambiar el valor contractual en razón de aumento o disminución - que no puede superar el 25\% del valor inicial del contrato- cuantitativa de su objeto (artículo 65, I, 77 a 80, ley 8.666/93).

Es interesante notar que en el caso de supresión por parte del poder público de obras, bienes o servicios, el tesoro deberá pagar los costos acreditados de adquisición de materiales monetariamente actualizados, si el contratista ya los hubiera comprado y puesto en el local de ejecución del contrato. En esta hipótesis, también es aplicable una indemnización por daños y perjuicios, siempre que se acredite que los daños fueron causados por la supresión y se demuestren los gastos. ${ }^{19}$ Del mismo modo, los impuestos o tasas creados, alterados o abolidos, así como las sobrevinientes disposiciones normativas, cuando ocurran después de presentada la propuesta y tienen comprobada repercusión en los precios contratados, darán lugar a una revisión para reajustarlos según el caso ${ }^{20}$.

Hay que hacer hincapié en que la alteración del valor contractual, para hacer frente al reajuste de precios establecido en el propio contrato, a las actualizaciones, compensaciones o sanciones financieras debidas a las condiciones de pago fijadas, así como al compromiso de dotaciones presupuestales adicionales hasta el límite de su valor actualizado, no constituye modificación del contrato y puede ser registrada como simple apostilla sin celebrar una adenda (artículo 65, párrafo 8).

A pesar del poder de modificar unilateralmente el contrato, la administración no puede dejar de cumplir con las disposiciones constitucionales que otorgan el contradictorio y la amplia defensa, cuando sea apropiado. Con relación a este tema, los tribunales nacionales han decidido que las alteraciones que se producen durante la ejecución del contrato deben ser registradas por medio de una cláusula adicional:

recurso especial letra "a" - administrativo - contrato de suministro de productos medicinales - alteración del precio del producto por dos ordenanzas - conversión del cruzeiro real para el real - juzgado que consideró legal la adopción de valor diverso de la paridad de cr\$2.750,00 por un real -

19 Acuerdo (decisión colegiada) 297/2005 - Plenario - Proceso 008.567/2004-6 - TCU - Número Interno del Documento AC-0297-09/05-P. Resumen: Estúdio de Auditoría. Furnas. Obras de implementación del sistema de transmisión Ouro Preto - Vitória, en la région sureste. Ejecución parcial de las obras. Gestión irregular de los contratos. Indebida renegociación de los. Pago con carácter retroactivo. Retraso en la liberación de la licencia ambiental. Acogimiento de las razones de justificación. Determinación. Archivado.

20 En los términos del artículo 65, párrafos 4,5 y 6, cuando hubiese alteración unilateral del contrato que resulte en aumento de los gastos del contratista, la administración deberá restablecer, por enmienda, el equilibrio económico-financiero inicial. 
ilegalidad de la ordenanza n. 103, de 22 de junio de 1994, que adoptó cr\$3.013,00 por un real. falta de prequestionamento" del artículo 334 del código de proceso civil. Los parámetros utilizados por la Secretaria General de Administración del Ministerio de Salud para la fijación del importe a pagar por el suministro de cada unidad de la medicina CAPD - Diálisis Peritoneal Ambulatoria Continua no obedeció a los criterios legales para la conversión entre Cruzeiro Real, URV y Real, en la forma establecida por la Ley n. 9.069/95, resultado de la conversión de la Medida Provisoria n.596/94. La Ordenanza n. 103, de 22 de junio de 1994, con efectos a partir del 1 de julio de ese año, desatiende el parámetro legal de conversión de la moneda, reflejando en el pago de la medicina suministrada por el peticionario, que fue fijado en R \$ 10,00 por unidad. RSTJ vol. 181 p. 161. No es apropiado alegar la existencia de cláusula exorbitante en el contrato de suministro, es decir, la posibilidad de modificación unilateral por parte de la Administración. Sabemos todos que el administrador debe guiarse por el principio de la estricta legalidad, consagrado en la Carta Política de 1988 (artículo 37, caput). Así, el Secretario de Asistencia a la Salud del Ministerio no podría adoptar coeficiente superior a los $\mathrm{R} \$ 2.750,00$ para la conversión en Reales, lo que llevó al pago del producto por un precio inferior al estipulado por la ley ( $\mathrm{R} \$ 10,96$ por unidad), en evidente prejuicio para el administrado contratista. El contratista tiene derecho de recibir la justa remuneración por lo servicio prestado, de lo contrario se rompería el equilibrio económico y financiero del contrato. El cambio de moneda no podría dar lugar a la reducción de la cantidad paga por la medicina como resultado de la adopción de un criterio de conversión superior al legal, incluso bajo la justificación de disminución del presupuesto del Ministerio de la Salud ${ }^{21}$.

En esta misma línea, es candente también la cuestión del equilibrio económico-financiero de los contratos suscritos por el poder público, también llamada "ecuación económico-financiera" y aquí concebida como el ajuste inicial acordado entre la administración y el contratista sobre el pago del precio del negocio jurídico celebrado. Ocurriendo alteraciones en el contrato que resulten en un desequilibrio en esta ecuación, correrá por cuenta de la administración adecuar las condiciones contractuales con el objeto de restablecer el equilibrio económico-financiero de la relación.

Esta recomposición está prevista en la Ley de Licitaciones para las situaciones en las que exista una modificación del plazo contractual (artículo 57, párrafo 1, numeral I); para los casos en los que la administración utiliza su prerrogativa de modificar unilateralmente el contrato dentro 
de los límites establecidos en la ley (artículo 58, párrafos 1 y 2); así como en circunstancias en que la recomposición se debe a acontecimientos previsibles o imprevisibles cuyas consecuencias sean incalculables (artículo 65 , letra "d"), aunque se requiere la demostración de la ruptura de este equilibrio para su restablecimiento.

Téngase en cuenta que esto solo es posible cuando el desequilibrio en la ecuación de los contratos ocurre después de que el acuerdo entra en vigor, por lo que la ley establece las hipótesis de revisión contractual ante las condiciones inicialmente acordadas, restringiendo su posibilidad a los supuestos fijados en ley.

La relación que se establece a la celebración del acuerdo es intangible por acto del poder público y, como tal, debe mantenerse durante toda la duración del contrato, a fin de que no se imponga indebida reducción de las utilidades normales de la empresa. Esto significa que, al utilizar su derecho de modificar unilateralmente las condiciones contractuales (artículo 58, párrafo 1, de la Ley de Licitaciones y Contratos Administrativos), la administración no puede violar el derecho del contratista de que sea mantenida la ecuación financiera originalmente establecida, y deberá realizar los ajustes necesarios para su recomposición.

De esta manera, el reajuste de precios y tarifas debe ser una medida de adecuación del negocio frente a las fluctuaciones económicas — variaciones de la política económica e inestabilidad monetaria - para posibilitar el mantenimiento del equilibrio financiero entre las partes.

Esta es la razón por la cual la ley 8.666/93 permite que los contratos administrativos sean enmendados para mantener ese equilibrio (artículo 65, II, d), párrafo 6). En la misma dirección, la Constitución Federal, en su artículo 37, XXI, dispone que obras, servicios, compras y ventas sean contratados con cláusulas que establezcan obligaciones de pago, de forma tal que las condiciones fijadas en la propuesta sean mantenidas.

Celso Antonio Bandeira de Mello ${ }^{22}$ hizo hincapié en que este equilibrio está disciplinado en otra norma constitucional, que es el artículo 5, XXXVI, que dispone que la ley no perjudicará el derecho adquirido, el acto jurídico perfecto y la cosa juzgada. Sin duda, la ecuación económica-financiera del contrato administrativo constituye un derecho adquirido del contratista, que no podrá ser afectado por las normas que lo regulan.

Se trata de un principio que protege el valor reajustado en un contrato a fin de mantener el equilibrio que debe guiar la actividad contratada ante la carga financiera correspondiente: "El tiempo no tiene la capacidad de modificar o eliminar esta relación de adecuación; sin embargo, podrán 
ocurrir variaciones. Vale la pena poner énfasis en que estas variaciones jamás podrán romper el equilibrio de la ecuación económica-financiera del contrato" ${ }^{\prime 2}$.

Evidentemente, es admisible, incluso para el ordenamiento jurídico, que los contratos administrativos en Brasil enfrenten situaciones de inestabilidad generadas por hechos imprevisibles, que configuren una situación intolerable solamente a una de las partes $\longrightarrow$ incluso a las dos—. De ahí resurge la fuerza imperativa de la histórica cláusula rebus sic standibus, que impone la inmediata revisión de lo acordado. Por lo tanto, en el ámbito administrativo, cada vez que la relación contractual sea desequilibrada por la ocurrencia de un hecho imprevisible, es justificable la revisión contractual para adaptarlo a la nueva realidad.

Nuevamente, el enfoque de Celso Antonio resulta preciso:

El riesgo que las partes asumen al celebrar un contrato no puede ser concebido como excediendo el riesgo normal, es decir, lo que está comprendido en los límites de la previsión humana. Llevar más allá el dogma de la intangibilidad del contrato sería, bajo el pretexto de garantizar la libertad contractual, destruir el fundamento del contrato, su base económica y moral, como instrumento del comercio y de la cooperación entre los hombres, el elemento de buena fe y de justicia sin el cual la libertad de los contratos sería una mera apariencia destinada a legitimar el enriquecimiento injusto de una parte a expensas del patrimonio de la otra, infligiendo exclusivamente a esta parte los riesgos ajenos a la naturaleza del contrato y que, si fueran previsibles en el momento de la contratación, habrían impedido la celebración del contrato. [...] el poder, disfrazado en derecho, de aprovecharse de las circunstancias imprevistas y anormales para convertir un instrumento de equilibrio económico, como es el contrato, en un instrumento de extorsión o enriquecimiento injusto. De ahí, la existencia de la teoría de la imprevisión. ${ }^{24}$

Como bien advierte Helly Lopes Meirelles ${ }^{25}$, la regla de la conservación del equilibrio económico-financiero está establecida desde el decreto-ley 2.300/86 — anterior al Estatuto Jurídico de las Licitaciones y Contratos Administrativos - y repetida en la ley vigente (artículo 65, II, d), que autoriza la modificación consentida de las condiciones contractuales para restablecer la relación originalmente acordada por las partes entre los gastos del contratista y la retribución de la administración para la justa remuneración de su objeto, con el fin de mantener la ecuación económico-financiera inicial. Hasta entonces su aplicación estaba

23 Gomes de Matos, Mauro Roberto. O Contrato administrativo. Río de Janeiro: América Jurídica, 2002. p. 55.

24 Bandeira de Mello. Curso de Direito... Ob. cit., p. 587.

25 Meirelles, Hely Lopes. Ob. cit., p. 205.

CONSIDERACIONES CRÍTICAS SOBRE EL CONTRATO ADMINISTRATIVO EN BRASIL

CRITICAL CONSIDERATIONS ONTHE

MANAGEMENT CONTRACT IN BRAZIL 
fundada en la equidad y era aceptada por la jurisprudencia nacional que, siguiendo las decisiones del Consejo de Estado de Francia y estimulada por la doctrina, admitía la revisión de los contratos públicos en razón de hechos sobrevinientes y muy costosos para el contratista.

En la doctrina nacional, los hechos que autorizan la revisión del contrato son el hecho del príncipe, el caso fortuito y los casos de fuerza mayor. Se conoce como el hecho del príncipe toda la determinación estatal, positiva o negativa, general, imprevista e imprevisible, que sobrecargue de forma sustancial la ejecución del contrato administrativo. En este sentido, es esclarecedora la decisión judicial en la que se afirmó:

La novedosa cultura sobre el contrato administrativo incluye, como núcleo en el régimen del vínculo, la protección del equilibrio económico-financiero del negocio jurídico de derecho público, afirmación que se infiere del contenido de la legislación infraconstitucional específica (artículos 57, párrafo 1으, 58, párrafos 1ํ e 2º, 65 , II, d, 88, párrafos 5ํo e 6 , de la Ley 8.666/93). En efecto, la Constitución Federal al inscribir los principios esenciales del artículo 37 que iluminan la actividad de la administración según el criterio de la moralidad, pone de manifiesto la necesidad de mantener este equilibrio al hacer hincapié en las "condiciones efectivas de la propuesta". 2. Lo sucedido en enero de 1999, plasmado en la repentina devaluación de la moneda nacional (Real) frente al dólar de EE.UU., constituyó causa excepcional de mutabilidad de los contratos administrativos, con el fin de mantener el equilibrio económico-financiero entre las partes. 3. Brusco rompimiento de la ecuación económico-financiera del contrato. Imposibilidad de empezar la ejecución con prevención de daños mayores. (ad impossiblia memo tenetur). 4. Previendo la ley la posibilidad de suspensión del contrato por la verificación de la exceptio non adimplet contractus imputable a la administración, a fortiori, implica admitir detenerse el "inicio de la ejecución", cuando desde luego, verificable la incidencia de la "imprevisión" ocurrida en el interregno en el que la administración pospuso los trabajos ${ }^{26}$.

Cuando de estos hechos se derivan perjuicios al contratista, surge la obligación estatal de compensarlos enteramente. En lo que respecta al llamado "hecho de la administración", que significa aquella acción u omisión de la administración pública que, incidiendo directa y específicamente sobre el contrato, impide su ejecución, igualmente aparece el deber de indemnizar el contratista por los perjuicios causados.

En cuanto a los conceptos de fuerza mayor y caso fortuito, provenientes de la institución jurídica de Derecho civil, consagrada en el 
artículo 393 del Nuevo Código Civil Brasileño ${ }^{27}$, el deudor no es responsable por los daños derivados de caso fortuito o fuerza mayor, si no les dio causa. Mientras la fuerza mayor se presenta como un acto humano imprevisible e inevitable que impide la ejecución del contrato, el caso fortuito representa un evento derivado del azar de la naturaleza, que es igualmente imprevisible e inevitable ${ }^{28}$.

En otras palabras, y en teoría, si ocurriese el evento de fuerza mayor o de caso fortuito, evaluado con gran detalle el impacto de la coyuntura en el negocio jurídico celebrado, el contratista puede alegar que no se puede esperar el cumplimiento del contrato si, frente a circunstancias ajenas a su voluntad y la definitiva inestabilidad del acuerdo, el cumplimiento del contrato resulta imposible o determina la ruina de su empresa.

En cuanto al reajuste de precios, esta posibilidad ocurre cuando existe previsión expresa en el contrato; de lo contrario, la necesidad de revisión podrá derivar de otras causas y justificativas que deberán ser examinadas en el caso concreto. Por lo tanto, el reajuste de precios puede ser traducido como la actualización del valor del contrato, relacionada al aumento de los costos de ejecución de su objeto frente al curso normal de la economía.

El reajuste de precios está disciplinado en el artículo 4 de la Ley de Licitaciones, que establece que la actualización debe reflejar la variación real del costo de producción, desde la fecha de presentación de la propuesta hasta la fecha de ejecución de cada etapa del contrato. Este reajuste se basará en los índices previamente fijados por el contrato, después de transcurrir doce meses a partir de la fecha de presentación de la propuesta o del presupuesto a que se refiera.

Como puede verse, el reajuste de precios es una facultad otorgada a la administración para evitar el rompimiento del equilibrio económicofinanciero del acuerdo inicial. Sin embargo, cabe señalar que el reajuste es una institución diferente de la revisión, pues constituye una cláusula contractual, previamente establecida, que trata sobre la necesidad de alteración de los precios pasado el período de doce meses, conforme se ha señalado ${ }^{29}$.

27 Antiguo artículo 1.058 del Código Civil Brasileño de 1916. Alerta el dispositivo actual, en su párrafo único, que el caso fortuito y de fuerza mayor se verifican en el hecho necesario, cuyos efectos no se podrían evitar o impedir.

28 En este sentido, véase la obra de Pereira, Caio Mário da Silva. Instituições de Direito civil. Volumen 1. Forense. Río de Janeiro: 2003, p. 88 y siguientes. Asimismo Lopes, Miguel Maria de Serpa. Curso de Direito civil. Volumen 1. Freitas Bastos. Río de Janeiro: 2001, p. 118 y siguientes.

29 Por consiguiente, si el contrato no establece el reajuste y si no ocurriera ninguno de los supuestos fijados en el artículo 65, II, "d", o en el párrafo 5 del mismo dispositivo, es decir, el aumento de impuestos o tasas legales, con demostrado impacto sobre los precios, la revisión no será posible y, por lo tanto, los precios se mantendrán inmodificables. 
De modo distinto, la revisión podrá ser aplicada independientemente de previsión contractual, como ocurre en los supuestos de superveniencia de hechos imprevisibles, o previsibles pero de consecuencias incalculables, según lo dispuesto en el artículo 65, II, letra “d”, de la ley 8.666/93.

Otro tema relevante en este sentido es lo que señalado con relación a la posibilidad de aplicar a los contratos administrativos nacionales la excepción de incumplimiento contractual. Téngase en cuenta que en el marco del Derecho civil, si una parte no cumple con lo acordado, la perjudicada tiene derecho de oponerle la llamada exceptio non adimplenti contractus para rechazar la pretensión de aquel que, aunque sea incumplidor, quiere reclamar la ejecución del contrato. Se trata del principio de la reciprocidad de las prestaciones que orienta los contratos privados, conforme dispone el artículo 476 del Nuevo Código Civil Brasileño.

En el marco del contrato administrativo, en vista del principio de continuidad del servicio público, la interrupción en la ejecución del negocio contractual no resulta recomendable. Sin embargo, este punto da lugar a controversias. En efecto, la doctrina especializada en el tema resalta las situaciones en las cuales el incumplimiento por la administración implica una sobrecarga extraordinaria e insoportable para el contratista - largo retraso en los pagos que obliga al contratista acogerse a la financiación de las obras y servicios no prevista en el contrato-, o incluso cuando ocurren casos de fuerza mayor o caso fortuito, como calamidades públicas, graves perturbaciones de la orden social, etcétera ${ }^{30}$.

Va en este sentido el artículo 78, XV, de la Ley de Licitaciones y Contratos Administrativos que, solo considerando los casos extremos, establece lo siguiente:

Constituye motivo para la rescisión del contrato: [...]; V - el retraso que supera los 90 (noventa) días en los pagos, o parte de ellos, debidos por la Administración en virtud de obras, servicios o suministros, ya recibidos o ejecutados, salvo en los casos de calamidades pública, grave perturbación del orden interna o de guerra, garantizado al contratista el derecho de optar por la suspensión del cumplimiento de sus obligaciones hasta que la situación se normalice.

Del mismo modo, Marçal Justen Filho ha sostenido reiteradamente que la prohibición de aplicar la excepción de incumplimiento contractual deriva del interés público y, por esta razón, no puede ser objeto de una maniobra maliciosa por cualquiera de las partes. La administración no tiene derecho a exigir el cumplimiento de las obligaciones contractuales

30 Debe advertirse que, si bien la ley otorga al contratista la facultad de suspender la ejecución del contrato después de transcurridos más de 90 días sin que la administración pague el precio contratado, se trata en realidad de un derecho del contratista, a pesar de que algunos autores vean como necesaria la intervención judicial. 
por parte del contratista cuanto, al mismo tiempo, está decidida a no cumplir el contrato ${ }^{31}$.

Celso Antonio Bandeira de Mello discrepa de esta postura. Plantea que la excepción de incumplimiento contractual puede ser invocada, pues el artículo arriba mencionado establece expresamente esta posibilidad, así como lo hace la disposición legal anterior, que autoriza la suspensión de la ejecución por orden escrita de la administración por un período superior a 120 días, o por repetidas suspensiones que totalicen el mismo tiempo, y le facultan a suspender el cumplimiento de sus obligaciones $\mathrm{u}$ obtener la rescisión del contrato ${ }^{32}$.

En mi opinión, igualmente no se podrá acoger esta regla cuando la interrupción de la ejecución contractual pueda implicar algún perjuicio directo a la población, como ocurriría en el caso de la rescisión del contrato de transporte colectivo, o también en los supuestos del artículo 78, XIV. Es decir, cuando la administración pública, al suspender un contrato, no indemniza las pérdidas del contratista. Cabe señalar que esta interpretación no es pacífica, por lo menos no con respeto a todos los contratos administrativos. Maria Helena Diniz cree que "En los contratos administrativos, mientras el poder público puede invocar la exceptio non adimplenti contractus contra el contratista que incumple el contrato, este no podrá hacer lo mismo, en virtud del principio de la continuidad del servicio público. A pesar de la inaplicabilidad de esta excepción a los contratos de servicio público, su invocación sería admisible en otros tipos de contratos administrativos" ${ }^{33}$.

Asimismo, Diógenes Gasparini afirma que, exceptuados los casos de, por ejemplo, contrato de concesión de servicio público (transporte colectivo, servicios funerarios) o de suministro de bienes necesarios al mantenimiento de un servicio público (almuerzos escolares, comidas de presos $\mathrm{u}$ hospitalizados, medicinas hospitalarias), la invocación de la exceptio non adimpleti contractus es perfectamente aplicable ${ }^{34}$.

Me parece que esta interpretación es más acorde con la realidad actual de las relaciones jurídicas que aparecen marcadas —o que deberían estar marcadas - por indicadores normativos de equilibrio, sensatez, ponderación, razonabilidad, tanto con relación a los objetos que alcanzan las disposiciones de voluntad, como a los propios intereses involucrados.

En lo que concierne al control, supervisión, monitoreo e intervención en los contratos administrativos, estos son atributos inherentes al poder público

31 Justen Filho, Marçal. Comentários à lei de licitações e contratos administrativos. São Paulo: Dialética, 2002, p. 528 y siguientes.

32 Bandeira de Mello. Curso de Direito... Ob. cit.

33 Diniz, Maria Helena. Tratado teórico e prático de contratos. Volumen 5. São Paulo: Saraiva, 1996, p. 334.

34 Gasparini, Diogenes. Direito administrativo. São Paulo: Saraiva, 1993, p. 427.

CONSIDERACIONES CRÍTICAS SOBRE

EL CONTRATO

ADMINISTRATIVO

EN BRASIL

CRITICAL

CONSIDERATIONS

ONTHE

MANAGEMENT

CONTRACT IN

BRAZIL 
para que garantice la perfecta realización del objeto contractual y la fiel observancia de sus cláusulas (aspectos técnicos de la obra o servicio, cronograma de trabajo, calidad de los materiales), aunque no estén expresamente incluidos en el contrato, o se desprendan de lo dispuesto en el artículo 58, III, de la ley 8.666/93.

Además, la administración tiene el deber de vigilar la ejecución del contrato respecto del interés público indisponible implicado; puede intervenir pero sin afectar la autonomía de ejecución del contratista, debidamente prevista en el contrato. Esta es la previsión del artículo 67 de la citada ley, que establecer que la ejecución del contrato deberá ser monitoreada y supervisada por un representante especialmente nombrado por la administración, y que está autorizada la contratación de terceros para asistirlo y prestarle las informaciones pertinentes. Este representante tomará nota, en libro propio, de todas las ocurrencias relacionadas con la ejecución del contrato y determinará lo que sea necesario para la regularización de las faltas o defectos observados ${ }^{35}$.

Recuérdese que la finalidad de la supervisión es garantizar la perfecta ejecución del contrato y la correspondencia exacta de la obra con el proyecto, tanto en sus aspectos técnicos como en su cronograma de trabajo. De ahí que sea posible una intervención dirigida a restablecer el orden y el fiel cumplimiento de lo acordado, independientemente de la orden judicial, pero con fundamento sólido y suficiente en el ámbito del debido proceso administrativo.

Consecuencia de este poder administrativo es la imposición de sanciones directas (artículo 58, IV, y 87, de la Ley de Licitaciones y Contratos Administrativos), por parte de la administración, pues sería inútil el control, la supervisión y la intervención en los contratos sin la posibilidad de sancionar el contratista si la ejecución del objeto no se encuentra dentro de los parámetros acordados. Sin embargo, esta prerrogativa del poder público está estrictamente vinculada con las normas constitucionales e infraconstitucionales pertinentes (debido proceso legal, amplia defensa, etcétera).

A pesar de todo lo señalado, cualquiera de estas cláusulas institucionales - así como cualquier acto administrativo- debe ser tratado con la debida razonabilidad y ponderación de todos los intereses implicados, pues,

35 Según el artículo 67 de la Ley de Licitaciones y Contratos Administrativos. Desde el artículo 68 de la misma ley, se puede verificar que el contratista está obligado a mantener un agente, aceptado por la administración, en el lugar de la obra o servicio, para que lo represente en la ejecución del contrato, así como debe reparar, arreglar, retirar, reconstruir o reemplazar, a su cargo, en la totalidad o en parte, el objeto del contrato que presente vicios, defectos o inexactitudes resultantes de la ejecución o de los materiales utilizados. Igualmente, él es responsable de los daños causados directamente a la administración o a terceros, que surjan de su culpa o dolo en la ejecución del contrato, sin excluir o reducir esa responsabilidad la supervisión o el monitoreo por el organismo interesado, así como por los costos laborales, de la seguridad social, tributarios y comerciales resultantes de la ejecución del contrato. 
de lo contrario, pueden generarse desequilibrios contractuales ilícitos y nocivos a los contratantes. Es decir, los juicios de proporcionalidad de los actos y medidas contractuales se imponen en cada situación particular, para que se pueda evaluar la relación entre el fin deseado y los medios utilizados, con el sentido teleológico o finalista, y se considera arbitrario el acto que no tenga en cuenta que los medios para lograr un propósito no son, por sí mismos, adecuados o cuando la desproporción entre el fin y los medios empleados para lograrlo sea particularmente evidente.

Este juicio de proporcionalidad ya es conocido por las teorías de la constitución y la administración pública contemporáneas, y se singulariza por las siguientes características: ${ }^{36}$

a. exige la conformidad o adecuación de los medios que requiere la investigación y la prueba de que el acto es congruente con los propósitos que justifican su adopción (relación de adecuación medio-fin), es decir, si la medida es susceptible de lograr el objetivo elegido;

b. respeta el principio de la necesidad o de la menor injerencia posible, que impone que los medios elegidos para alcanzar un fin determinado deben ser los menos costosos; de ahí la búsqueda de la necesidad material (el medio elegido debe afectar lo menos posible los derechos fundamentales), exigibilidad espacial (debe ser bien definido el alcance de la intervención), exigibilidad temporal (también requiere una rigurosa delimitación de la duración de la intervención del poder público), y exigibilidad personal o individualización de las limitaciones (la medida adoptada se debe limitar a la persona o personas cuyos intereses están implicados);

c. tiene en cuenta el principio de la proporcionalidad en sentido restricto, según lo cual los medios y los fines son puestos en una ecuación de juicio de ponderación, con la finalidad de evaluar si el medio utilizado es proporcional o no al fin pretendido ${ }^{37}$.

36 Debe anotarse que, a pesar de que la Constitución Brasileña de 1988 no trata explícitamente sobre este principio - como sí lo hace la Constitución de Portugal- existen mención implícita en diversos dispositivos: (a) el principio de adecuación de los medios, en el artículo 138, que se refiere a las garantías constitucionales que quedaron suspendidas durante el Estado de Sitio; (b) el principio de necesidad, en el artículo 37, IX, sobre la contratación por tiempo determinado de personal para atender a necesidades transitorias de excepcional interés público; (c) el principio de proporcionalidad en sentido estricto, en el artículo 173, que señala que, además de los casos previstos en la Constitución, una explotación directa de actividad económica por parte del Estado solo será permitida cuando resulte necesaria según a los imperativos de la seguridad nacional o un relevante interés colectivo, conforme lo defina la ley.

37 Canotilho, José J. Gomes. Direito constitucional. Coímbra: Almedina, 1998, p. 386. El autor advierte que, en general, no se discute la adopción de la medida en sí misma, pero sí opina que la autoridad pública pudo haber adoptado otra medida igualmente eficaz y menos perjudicial para los ciudadanos. Mientras tanto, Larenz insiste en el hecho que ponderar y sopesar es solamente una imagen. No se trata de grandezas cuantitativamente medibles, sino el resultado de valoraciones que -ahí está la mayor dificultad — no solo deben dirigirse a una pauta general, sino también a la situación concreta en cada caso (Larenz, Karl. Metodologia da ciência do Direito. Lisboa: Fundação Calouste Gulbenkian, 
En otras palabras, si es cierto que la realización de estos derechos supone una optimización de las situaciones jurídicas y de hecho, es evidente que la adecuación de los medios a los fines, así como la búsqueda de mayor idoneidad del medio para lograr el fin, están implícitas en el proceso porque son ellas que determinan el resultado bajo la realidad posible.

Moreira Neto ${ }^{38}$ advierte insistentemente que este principio alcanza tanto la norma jurídica positiva que dispone sobre la acción estatal, cuanto el acto administrativo que la autoriza; es decir, todos están limitados por la proporcionalidad entre los sacrificios impuestos y la ventaja general obtenida. El autor afirma que "cuando esta relación no es equilibrada hasta el punto de tornar onerosa la ejecución positiva o negativa, para el contratista, en comparación con el reducido o nulo beneficio para la sociedad, la fuerza del principio produce la terminación del negocio jurídico".

Con respeto a los plazos de los contratos administrativos, conviene señalar que la legislación vigente prohíbe la existencia de ajustes por tiempo indeterminado, ya que la duración de los contratos debe limitarse a la duración de la dotación presupuestaria, con las siguientes excepciones:

a. los contratos relativos a proyectos cuyos productos están incluidos en las metas del presupuesto anual aprobado por ley (artículo $57, \mathrm{I})$;

b. los contratos de prestación de servicios que se ejecutarán continuamente, sin exceder cinco años; estos contratos pueden prorrogarse, pero solo podrán comprometer $25 \%$ del valor original del contrato y los plazos deben ser ajustados para obedecer a este límite legal;

c. los contratos de locación de equipos y programas informáticos, cuya duración puede ser fijada para un máximo de 48 meses y está sujeta a los límites de extensión de los contratos de prestación de servicios continuos;

d. los contratos de seguro, financiación, leasing y otros semejantes a los privados; a pesar de no tener límite de duración, esta debe ser siempre determinada.

Es importante tener en cuenta que los contratos que superen el límite legal serán anulados, salvo en los casos en que se pueda invalidar solamente la cláusula en lo que exceda el límite legal. Si este ajuste no es

1997, p. 574). De todos los modos, el autor recuerda que esa ponderación puede estar basada en los principios de Derecho fundamental y en los principios del Estado de Derecho, y la llamada práctica judicial y el concepto de justicia (p. 576). En el mismo sentido escribe Alexy, Robert. Teoría de los derechos fundamentales. Madrid: Centro de Estudios Constitucionales, 1997, p. 265.

38 Ob. cit., p. 74. 
posible sin cambiar la sustancia del acuerdo, entonces el contrato debe ser anulado por completo. En este caso:

Administrativo. Acción popular. Procedimiento de licitación. Desobediencia a las disposiciones legales. Contrato por una suma grande. Designación de la modalidad "oferta de precios" en lugar de "concurso público". Inserción en el edicto de cláusulas restrictivas de la naturaleza competitiva del procedimiento, así como de cláusulas que permitían preferencias y distinciones injustificadas. Distorsión del principio de la igualdad entre los licitadores. Violación de los principios de la legalidad y moralidad administrativas. Lesión al erario público caracterizada. Nulidad ${ }^{39}$.

En esta oportunidad, el relator del proceso señaló que lo que debe inspirar el administrador público es la voluntad de hacer justicia para los ciudadanos, ser eficiente para con la propia administración y renunciar a cualquier beneficio, porque el cumplimiento del principio de la moralidad, además de constituirse un deber del administrador, es un derecho subjetivo de cada administrado. De esta forma, la actuación estatal meramente compatible con la orden legal no satisface los intereses de la nación, y la administración debe someterse a ciertos principios que conduzcan a la valorización de la dignidad humana, al respeto a la ciudadanía y a la construcción de una sociedad justa y solidaria.

Estas son solo algunas reflexiones sobre el complejo tema de los contratos administrativos en Brasil.

39 RESP 579541 / SP; DJ:19/04/2004; Relator Min. JOSÉ DELGADO; Primeira Turma. El relator enfatiza que la nulidad de la licitación o del contrato no podría oponerse a los demandantes que actuasen de buena fe. En el caso, por las conductas descritas, se verifica que hubo concurrencia entre los demandantes para concretar el acto de forma viciada, es decir, con su conocimiento. Por otra parte, la corte sostuvo que "[...] la indemnización por los servicios prestados requiere que el contratista haya actuado de buena fe, lo que no ocurrió en el caso. Los demandantes no son terceros de buena fe, pues participaron del acto, aprovechándose de su irregularidad. Lo que debe ser protegido es el interés de terceros que de cualquier modo se involucraron o contrataron con la administración en virtud del servicio prestado. La administración sólo tiene el deber de indemnizar el contratista si este no ha contribuido a los daños causados. El principio de la prohibición del enriquecimiento sin causa se basa en la equidad y en la moralidad, y, por ello, no puede ser invocado por quien celebró contrato con la administración violando el principio de la moralidad, actuando con comprobada mala fe".

\section{CONSIDERACIONES CRÍTICAS SOBRE \\ EL CONTRATO \\ ADMINISTRATIVO \\ EN BRASIL}

CRITICAL

CONSIDERATIONS

ONTHE

MANAGEMENT

CONTRACT IN

BRAZIL 